\title{
DOSCIENTOS AÑOS DESPUÉS. LA INFLUENCIA DE LA CONSTITUCIÓN ESPAÑOLA DE 1812 EN LAS CONSTITUCIONES LATINOAMERICANAS EN VIGOR. UNA APROXIMACIÓN
}

MANUEL MARTÍNEZ SOSPEDRA 
SUMARIO

1. INTRODUCCIÓN. 2. LA DISTRIBUCIÓN DEL PODER EN EL MODELO DOCEAÑISTA. 3. NACIONALIDAD Y CIUDADANÍA. 4. LA ORDENACIÓN DEL CONGRESO: ORGANIZACIÓN Y FACULTADES. 5. EL PODER EJECUTIVO. 6. LA AUSENCIA DEL PODER JUDICIAL. 7. CONCLUSIÓN. 


\title{
DOSCIENTOS AÑOS DESPUÉS. LA INFLUENCIA DE LA CONSTITUCIÓN ESPAÑOLA DE 1812 EN LAS CONSTITUCIONES LATINOAMERICANAS EN VIGOR. UNA APROXIMACIÓN
}

\author{
MANUEL MARTÍNEZ SOSPEDRA \\ Catedrático de Derecho Constitucional. UCH-CEU
}

\section{INTRODUCCIÓN}

En otro lugar he mostrado cómo la figura del Presidente de la República diseñada en las constituciones latinoamericanas de primera generación, las inmediatamente posteriores a la Independencia efectiva, se modeló a partir del patrón proporcionado por la figura del Rey diseñada en la Constitución española de 1812 , y, en particular, a partir de la versión reduccionista de las facultades del Ejecutivo diseñada por el Reglamento de la Regencia de $1813^{1}$. Obviamente esa influencia no es uniforme: es más acentuada en los textos constitucionales primerizos que se producen en Repúblicas que han vivido previamente un período de aplicación de la Constitución española ( los casos emblemáticos el de México y el del Perú), y lo es menos en el área bolivariana, siendo muy escasa en el caso de Argentina ( no así en el de Uruguay). Es más, el diseño general del re-

\footnotetext{
${ }^{1}$ Martínez Sospedra, M. La sombra del Rey. El ejecutivo de 1812 y las primeras constituciones latinoamericanas. En Colomer Viadel, A. ( coord.) Las Cortes de Cádiz, la Constitución de 1812 y las independencias nacionales en América. Amadís. Valencia.2011.
} 
parto del poder adoptado por los constituyentes españoles, del cual el diseño del poder ejecutivo es parte, tiene una marcadísima influencia, siendo de adopción ampliamente mayoritaria e influyendo seriamente incluso en textos constitucionales que adoptan el modelo de la Constitución del Año VIII con las reformas del Senadoconsulto del Año X, como sucede en los textos «vitalicios» peruano y boliviano de 1826. Sin duda alguna el grado máximo de influencia se da tres casos: el texto uruguayo de 1830 , el mexicano de 1824 y el chileno de 1833, lo que, como veremos, no deja de tener su importancia por lo que al Derecho Constitucional vigente corresponde. Las páginas que siguen tratan de constituir una aproximación, por fuerza imperfecta y provisional, a las supervivencias que el Derecho Constitucional Latinoamericano en vigor, registra de aquella influencia histórica.

La influencia doceañista posible no se trata de determinar a través de la técnica de la identidad o similitud de los enunciados constitucionales, por más que los casos en que esta se da sean cualquier cosa menos escasos. Más bien la similitud se busca no en los elementos componentes, sino en el diseño de la distribución del poder y en las posiciones respectivas que se atribuyen al Congreso y al Presidente de la República, si bien no debe sorprender que si hay coincidencia en el diseño no sea precisamente extraño que haya una fuerte influencia en los enunciados constitucionales, a veces con resultados sorprendentes, así, por ejemplo, la peculiar ordenación del mandato y de la elección de la Cámara Baja del Congreso argentino: mandato de cuatro años y renovación parcial por mitades cada dos, no es sino una aplicación a una elección legislativa del procedimiento diseñado por el art. 327 del texto gaditano para la elección de diputaciones provinciales.

A los efectos que aquí interesan se ha utilizado el texto español en la versión establecida por mi maestro ${ }^{2}$, que he contrastado con el original. Por lo que toca al Derecho Constitucional hispanoamericano vigente, a la vista de la dispersión del material, he recurrido a la versión que en cada caso figura en la web de la biblioteca virtual Cervantes ${ }^{3}$, a estos efectos en cada caso se ha escogido el texto constitucional completo de fecha más reciente, aun al precio de no contemplar en algunos casos enmiendas posteriores, que en algún caso pueden ser importantes ( Colombia,por ejemplo), lo que permite obtener un material que reúne el mínimo de homogeneidad que a estos efectos es exigible.

\footnotetext{
2 Sevilla Andrés, D. Constituciones y otras leyes y proyectos políticos de España. 2 v. EN.Madrid.1969 v.I. pp. 115 y ss. (incluye el Discurso Preliminar)

${ }^{3}$ Cervantesvirtual.com/ constituciones hispanoamericanas/ constituciones. Hay que advertir que en algún caso ( por ejem. Bolivia) el texto que figura no es el vigente a día de hoy.
} 


\section{LA DISTRIBUCIÓN DEL PODER EN EL MODELO DOCEAÑISTA}

Como el Derecho Constitucional Latinoamericano ha escogido desde el comienzo una forma de gobierno presidencial inspirada en el modelo sentado por el texto federal USA y su aplicación práctica, no debe sorprender que la tendencia espontánea del operador jurídico sea asignar una influencia preeminente del modelo USA en el diseño del sistema de gobierno latinoamericano, no es extraño que se haya convertido en tópico. Sin embargo la realidad muestra que las cosas son más complejas. No hay inconveniente en admitir que, conforme ha ido transcurriendo el tiempo y ha ido mutando en su práctica aplicación el diseño original de la Constitución USA, en la medida en que esta se ido deslizando desde la posición inicial de un Presidente electo por notables que ejerce en comité los poderes presidenciales, hasta derivar en un presidente de elección popular escogido por el pueblo en la única elección auténticamente nacional, que opera como líder nacional y motor del Congreso. Parece adecuado anotar a favor de esa influencia creciente de un modelo que proviene en lo fundamental de la revolución jacksoniana el abandono de la elección presidencial parlamentaria o cuasiparlamentaria tan frecuente en el constitucionalismo latinoamericano de primera generación a favor de la elección popular directa, con la deriva a favor del «ballotage con desempate», de claro perfil galo, a partir de los años sesenta del siglo pasado.

Ahora bien, si se procede a un examen comparativo entre la regulación constitucional del sistema de gobierno en la Constitución norteamericana y el correspondiente de cualquiera de las latinoamericanas, con la posible excepción del texto argentino de 1853, pronto salta a la vista que nos hallamos ante criaturas diferentes. Poco menos que desde la fundación de la República el derecho constitucional de la América hispana difiere sustancialmente del diseño que contiene el texto USA de 1787 y sus enmiendas. En el caso latinoamericano no es difícil encontrar un patrón común: la constitución se abre con la determinación de nacionalidad, ciudadanía y causas de suspensión de esta, sigue por una regulación del Congreso ajustada a un patrón uniforme: reglas sobre estructura, composición, elección y funcionamiento de la Legislatura a las que sigue un definición exhaustiva de la esfera de competencia de ésta mediante la técnica de una relación extensa y detallada de las atribuciones del Parlamento, a las que sigue la regulación de la producción legislativa para finalizar las más de las veces, pero no siempre, con la regulación de la prórroga de las sesiones, del régimen de sesiones extraordinarias y, con frecuencia, de un órgano similar a la Diputación Permanente española. A renglón seguido procede la regulación del Ejecutivo, que se encomienda a un Presidente, dotado frecuentemente de una cláusula definitoria, cu- 
yos poderes se determinan mediante una relación exhaustiva de facultades, a lo que sigue una regulación de secretarios del despacho y algunas veces un consejo del Presidente. Le sigue una ordenación del Poder Judicial, casi siempre tripartita, aunque no faltan los casos en los que a los tres niveles de organización encomendada a jueces profesionales se agrega un cuarto de jueces legos, casi siempre le sigue un conjunto de reglas sobre los gobiernos locales, la fuerza armada, la hacienda y la reforma constitucional. Resulta obvio que un diseño así no se parece en nada al propio del texto federal norteamericano.

Cabría la posibilidad de buscar a dicha estructura precedentes en el derecho constitucional francés del período fundacional. En este sentido es obvia la influencia de la Constitución del Año III en los textos venezolano de 1811 y mexicano de Apatzingán, asi como en algunas constituciones provinciales de la Nueva Granada, influencia que se extiende a algunos de los primeros textos argentinos o chilenos, que aun cuando contemplen un ejecutivo unipersonal los definen como «Director del Estado», asi como se aprecia una cierta influencia del texto de 1791 en la definición del Presidente como administrador general de la República que introdujo el texto venezolano de 1819 y tan popular fue en los textos de primera generación. Por lo demás resulta obvia la influencia del constitucionalismo napoleónico en los textos vitalicios bolivarianos de Bolivia y Perú. Sin embargo la estructura que se ha descrito no se corresponde con la propia de los textos franceses de la época. El hecho de que la misma estructura aparezca en tanto en las Constituciones del área bolivariana como fuera de ella, apunta a un precedente general. Y este resulta muy claro: la Constitución española de 1812.

En efecto es en texto español donde se puede encontrar el diseño de la estructura que acabo de señalar, diseño que incorpora una concepción de los poderes diferente de la que cabe hallar en el texto norteamericano. Nunca se ha discutido seriamente que la organización judicial de las nuevas repúblicas y de su procedimiento debe poco al precedente norteamericano y mucho al de la Monarquía, al fin y al cabo la estructura misma del sistema jurídico es radicalmente distinta: en USA rige uniformemente un sistema legal de common law $w^{4}$ que exige un tipo especifico de judicatura. Pero no ha tenido en cuenta de que tanto la concepción del Legislativo como la del Ejecutivo son diferentes en el caso USA y en el latinoamericano, razón por la cual la estructura de los textos es diferente. En el caso USA no existe propiamente una enumeración de las facultades del Congreso, lo que hace la sección octava del art. 1 de la Constitución federal es diseñar la esfera de competencia federal, el poder del Congreso tiene una definición

\footnotetext{
${ }^{4}$ Con una excepción: Luisiana tiene un sistema legal de «derecho civil».
} 
genérica, la que se halla en la sección primera del mismo artículo: el Congreso es titular de «todos los poderes legislativos otorgados en la presente Constitución». Y algo similar sucede con el Presidente. En este caso es cierto que el art. 2. contiene algunas atribuciones específicas: la cláusula de comandante en jefe, la facultad de indulto, el derecho a recabar información y el reparto del treaty making power con el Senado, no obstante lo cual la definición del poder presidencial es tan genérica como la del Congreso: «se encomienda el poder ejecutivo a un Presidente» reza la sección primera del artículo segundo. Y nada más. No es difícil referir tan vaga determinación del poder presidencial al concepto británico del poder regio como prerrogativa: su autoridad se extiende a todo el poder federal que la Constitución no asigna ni al Congreso ni a la judicatura. Que el Presidente hispánico sea titular de facultades del Rey que su homólogo USA no tiene ( iniciativa legislativa, promulgación y muy frecuentemente sanción, potestad reglamentaria, por ej.) no es sino la lógica consecuencia.

Ahora bien, si lo dicho puede sostenerse acerca de textos constitucionales como el mexicano de 1824 , los peruanos de 1823 y 1828 , el grancolombiano de 1821 o los chilenos de 1822,1828 y, sobre todo, de 1833, no implica que lo dicho sea eo ipso válido para los textos constitucionales actuales, cuya relación con la Constitución de Cádiz ni es inmediata, ni es precisamente evidente. Y es de eso de lo que aquí se va a tratar.

De entrada conviene precisar que parte de los contenidos de las constituciones hispanoamericanas vigentes no puede proceder de la influencia del texto español de 1812. Sintéticamente hay que anotar, en primer lugar, la declaración de derechos, el texto español de 1812 se caracteriza, entre otras cosas, por carecer de una exposición sistemática de los derechos individuales ubicada en una parte específica del texto, pudo ser de otro modo ${ }^{5}$, pero si bien el texto español reconoce derechos carece de una ordenación sistemática de los mismos; en segundo lugar no puede proceder de aquella influencia las muy extensas declaraciones de derechos sociales y colectivos tan típicas del derecho constitucional latinoamericano reciente, como mucho puede detectarse alguna influencia muy secundaria en aquellos casos en los que el texto constitucional establece explícitamente deberes, a imagen y semejanza de los arts. 6 a 9 del texto español; en tercer lugar es necesariamente ajeno al texto español el conjunto de reglas que ordenan la elección y eventual sustitución del Presidente de la República, punto en cual es palpable la influencia estadounidense; en cuarto lugar no puede

\footnotetext{
${ }^{5}$ De hecho la «fracción de comisión» que redactó el proyecto alcanzó a redactar una,pero acabó decidiendo no incorporarla. Vide Martinez Sospedra,M. La Constitución de 1812 y el primer liberalismo español. Valencia.1978 pp. 159/62.
} 
proceder del texto español y su influencia la organización del Congreso cuando este es bicameral, dada la concepción monista de la Legislatura por la que optaron los doceañistas; en quinto lugar es necesariamente ajeno a la influencia gaditana el sistema de justicia constitucional, escasamente compatible por lo demás con el sistema de fiscalización parlamentaria del cumplimiento de la ley fundamental previsto en el texto español y presente en algunos de sus hijos, como el mexicano de 1824; finalmente no pueden proceder de la influencia gaditana las normas constitucionales sobre relaciones exteriores, minorías indígenas ${ }^{6}$ o integración regional.

Hay una cuestión en la que la reglamentación es per se ambigua: la organización judicial. En esta materia tanto el modelo norteamericano, como el francés, como el doceañista optan por un sistema judicial estructurado en tres niveles de órganos judiciales servidos por jueces profesionales, en este punto las diferencias son menores y se reducen a algunas cuestiones de competencia y, a veces, a la denominación. Como mucho cabría señalar que el modelo gaditano obedece a una estructura 3 + 1: jueces de partido, audiencias, supremo, todos servidos por jueces profesionales, y en la base de la pirámide un escalón de jueces legos (primero alcaldes, luego jueces de paz). Es cierto que no son raros los casos en los que debajo de la denominación de la Corte de Circuito son perceptibles las puñetas de los jueces de la Real Audiencia, pero esta es cuestión que requiere de un análisis mucho más detallado, que exige la consideración minuciosa de la legislación ordinaria sobre el derecho de la jurisdicción que ciertamente no es de este lugar.

El texto español recibe una ordenación particular: se abre con una serie de normas de principio que definen la nación, la soberanía nacional, la nacionalidad, los deberes cívicos y una enumeración detallada del territorio, le sigue una breve definición del gobierno y la separación de poderes, continúa con una regulación de la ciudadanía y de su suspensión para pasar a regular la elección de las Cortes, su organización y modo de funcionamiento. A renglón seguido se define la esfera de competencia de la Legislatura mediante una técnica muy particular: una detallada y numerosa enumeración de facultades, le sigue la ordenación del proceso de producción legislativa, que incluye el veto, la sanción y la promulgación por el Rey, cerrándose la regulación del Parlamento con las reglas sobre prórroga, sesión extraordinaria y Diputación Permanente. Concluido el régimen

\footnotetext{
${ }^{6}$ De hecho la única referencia gaditana a la población indígena es indirecta: el art.18 les reconoce como ciudadanos y, en consecuencia, titulares de los derechos de sufragio activo y pasivo, incluso las Cortes llegaron a adoptar un decreto específico para adaptar el régimen municipal a los casos de poblamiento disperso que caracterizaban el asentamiento de una parte de la población originaria.
} 
de las Cortes le sigue la del Ejecutivo, ésta se abre con una cláusula definitoria a la que se anuda una determinación detallada de las facultades del Rey, a la que se asocian los supuestos en los que es exigible la intervención de las Cortes, so capa de restricciones, tras regular las figuras típicas de la forma monárquica se cierra la regulación del Ejecutivo con la regulación de los secretarios de Estado y el Consejo. A renglón seguido se opera la definición del poder judicial, con inclusión de las normas de principio sobre los procedimientos civil y criminal ( que aquí no se van a considerar). Finalizada la ordenación de los poderes se sigue con la propia de los gobiernos locales ( comprendida en ella la de los agentes del Ejecutivo en provincias), le sigue el régimen de la Hacienda, el de las Fuerzas Armadas, el de la enseñanza, y finaliza con el sistema de protección y reforma de la Constitución.

Para lo que sigue interesa destacar que el texto doceañista define al Legislativo y al Ejecutivo a partir de la noción romano-canónica de oficio ( por eso el texto habla de «potestad» y no de «poder» en los arts.15 a 17), concepción que se expresa tanto mediante una definición activista del Ejecutivo, como mediante una técnica particular que ya se ha señalado: la enumeración detallada de las atribuciones propias de la Cortes y de un Ejecutivo concebido como «gobierno». Lo primero separa el esquema de gobierno propio del texto español de los precedentes franceses ( de los cuales solo son relevantes dos: el de 1791 y el del Año III), lo segundo separa al mismo del paradigma norteamericano. De hecho, la razón que subyace al dato según el cual el Presidente de la República hispánico goza de iniciativa legislativa, potestad reglamentaria y promulgación de las leyes, cosas todas tres ausente en el modelo USA no es otra que esa concepción activista del poder ejecutivo entendido como «gobierno» que, procedente de la concepción jovellanista de la «función gubernativa», adopta el texto de $1812^{7}$.

Sentado lo anterior y con las muy importantes limitaciones que se han señalado cabe plantearse en qué medida la estructura del texto de 1812 se halla presente en el derecho constitucional latinoamericano actual. Un análisis sumario nos ofrece el perfil que figura en el Cuadro I:

\footnotetext{
${ }^{7}$ Aunque he tratado del tema en otras ocasiones vide Martinez Sospedra,M. El Rey como Poder Ejecutivo.La posición del Rey en la Constitución de 1812. En Corts. $N^{\circ}$ ex. Valencia.2011 ( en prensa).
} 


\section{Cuadro I. Estructura del texto}

\begin{tabular}{|l|c|c|c|c|c|c|c|c|c|c|c|c|c|c|c|c|c|}
\hline & Ar. & Bol. & Ch. & Col. & CR & Ecu & ES & Gua & Hon & Mex & Nic & Pan & Par & Perú & RD & Uru & Ven \\
\hline Territorio & & & & $\mathrm{x}$ & $\mathrm{x}$ & $\mathrm{x}$ & $\mathrm{x}$ & & $\mathrm{x}$ & $\mathrm{x}$ & $\mathrm{x}$ & $\mathrm{x}$ & & $\mathrm{x}$ & $\mathrm{x}$ & & $\mathrm{x}$ \\
\hline Gobierno & & & & $\mathrm{x}$ & $\mathrm{x}$ & & $\mathrm{x}$ & $\mathrm{x}$ & & $\mathrm{x}$ & $\mathrm{x}$ & & $\mathrm{x}$ & & $\mathrm{x}$ & & $\mathrm{x}$ \\
\hline Nac y ciudadanía & & $\mathrm{x}$ & $\mathrm{x}$ & $\mathrm{x}$ & $\mathrm{x}$ & $\mathrm{x}$ & $\mathrm{x}$ & $\mathrm{x}$ & $\mathrm{x}$ & $\mathrm{x}$ & & $\mathrm{x}$ & $\mathrm{x}$ & $\mathrm{x}$ & $\mathrm{x}$ & $\mathrm{x}$ & $\mathrm{x}$ \\
\hline Org.legislatura & $\mathrm{x}$ & $\mathrm{x}$ & & $\mathrm{x}$ & $\mathrm{x}$ & $\mathrm{x}$ & $\mathrm{x}$ & $\mathrm{x}$ & $\mathrm{x}$ & $\mathrm{x}$ & & $\mathrm{x}$ & $\mathrm{x}$ & $\mathrm{x}$ & $\mathrm{x}$ & & \\
\hline Facultades L. & & $\mathrm{x}$ & & $\mathrm{x}$ & $\mathrm{x}$ & $\mathrm{x}$ & $\mathrm{x}$ & $\mathrm{x}$ & $\mathrm{x}$ & & $\mathrm{x}$ & $\mathrm{x}$ & $\mathrm{x}$ & $\mathrm{x}$ & $\mathrm{x}$ & $\mathrm{x}$ & $\mathrm{x}$ \\
\hline Prod. Leg. & $\mathrm{x}$ & $\mathrm{x}$ & & $\mathrm{x}$ & $\mathrm{x}$ & $\mathrm{x}$ & $\mathrm{x}$ & $\mathrm{x}$ & $\mathrm{x}$ & $\mathrm{x}$ & $\mathrm{x}$ & $\mathrm{x}$ & $\mathrm{x}$ & $\mathrm{x}$ & $\mathrm{x}$ & $\mathrm{x}$ & $\mathrm{x}$ \\
\hline Dip.Permanen. & & $\mathrm{x}$ & & & & & & $\mathrm{x}$ & $\mathrm{x}$ & $\mathrm{x}$ & & & $\mathrm{x}$ & $\mathrm{x}$ & & $\mathrm{x}$ & $\mathrm{x}$ \\
\hline $\begin{array}{l}\text { Sesión } \\
\text { Extraordinaria }\end{array}$ & $\mathrm{x}$ & $\mathrm{x}$ & $\mathrm{x}$ & $\mathrm{x}$ & $\mathrm{x}$ & $\mathrm{x}$ & $\mathrm{x}$ & $\mathrm{x}$ & $\mathrm{x}$ & $\mathrm{x}$ & & $\mathrm{x}$ & $\mathrm{x}$ & & $\mathrm{x}$ & $\mathrm{x}$ & $\mathrm{x}$ \\
\hline $\begin{array}{l}\text { Facultades } \\
\text { P. Ejecutivo }\end{array}$ & $\mathrm{x}$ & $\mathrm{x}$ & $\mathrm{x}$ & $\mathrm{x}$ & $\mathrm{x}$ & $\mathrm{x}$ & $\mathrm{x}$ & $\mathrm{x}$ & $\mathrm{x}$ & $\mathrm{x}$ & $\mathrm{x}$ & $\mathrm{x}$ & $\mathrm{x}$ & $\mathrm{x}$ & $\mathrm{x}$ & $\mathrm{x}$ & $\mathrm{x}$ \\
\hline Ministros & $\mathrm{x}$ & $\mathrm{x}$ & $\mathrm{x}$ & $\mathrm{x}$ & $\mathrm{x}$ & $\mathrm{x}$ & $\mathrm{x}$ & $\mathrm{x}$ & $\mathrm{x}$ & $\mathrm{x}$ & $\mathrm{x}$ & $\mathrm{x}$ & $\mathrm{x}$ & $\mathrm{x}$ & $\mathrm{x}$ & $\mathrm{x}$ & $\mathrm{x}$ \\
\hline Gob.locales & & $\mathrm{x}$ & $\mathrm{x}$ & $\mathrm{x}$ & $\mathrm{x}$ & $\mathrm{x}$ & $\mathrm{x}$ & $\mathrm{x}$ & $\mathrm{x}$ & & $\mathrm{x}$ & $\mathrm{x}$ & $\mathrm{x}$ & $\mathrm{x}$ & $\mathrm{x}$ & & \\
\hline Hacienda & & $\mathrm{x}$ & $\mathrm{x}$ & $\mathrm{x}$ & $\mathrm{x}$ & $\mathrm{x}$ & & $\mathrm{x}$ & $\mathrm{x}$ & & & $\mathrm{x}$ & & & & & $\mathrm{x}$ \\
\hline FAS & & $\mathrm{x}$ & $\mathrm{x}$ & $\mathrm{x}$ & & & $\mathrm{x}$ & $\mathrm{x}$ & $\mathrm{x}$ & & & $\mathrm{x}$ & $\mathrm{x}$ & $\mathrm{x}$ & $\mathrm{x}$ & & $\mathrm{x}$ \\
\hline $\begin{array}{l}\text { Protección y } \\
\text { reforma Cons. }\end{array}$ & & & & $\mathrm{x}$ & $\mathrm{x}$ & $\mathrm{x}$ & $\mathrm{x}$ & & $\mathrm{x}$ & & & & & & $\mathrm{x}$ \\
\hline
\end{tabular}

Como puede verse, la parte inicial de los textos comporta una determinación del territorio de la República ( doce casos sobre diecisiete) le sigue una determinación genérica del gobierno en nueve casos sobre diecisiete, del mismo modo que figura una regulación de la nacionalidad, la ciudadanía y las causas de suspensión de esta última en quince casos sobre diecisiete. No parece que pueda decirse que aquella influencia es, en la parte señalada, precisamente débil. Si pasamos a la organización de los poderes fácilmente se comprueba que la plantilla doceañista: primero, organización del Congreso; segundo, facultades; tercero, producción legislativa; cuarto prórroga de las sesiones y sesiones extraordinarias, goza de buena salud. Si exceptuamos el texto chileno, que no es precisamente un ejemplo señero de la tradición liberal, y que acoge una regulación de distinta estructura en razón de la hegemonía presidencial y de la adopción de una concepción material de la $l^{8}{ }^{8}$, aquella plantilla es ampliamente dominante: se sigue fielmente en no menos de diez casos sobre diecisiete, se sigue parcialmente en cinco casos y solo el texto federal argentino y el citado de Chile escapan, bien que

${ }^{8}$ A la que me parece no es ajena la influencia de los art. 10 y 12 de la ley constitutiva de Cortes de 1942 . 
sea parcialmente a su influjo. Así la prioridad de la organización de la Legislatura se da en trece casos, la enumeración taxativa de las atribuciones del Congreso se da en los catorce casos en que es pertinente ${ }^{9}$, la regulación de procedimiento legislativo sigue siempre a la de las atribuciones del Congreso, salvo en Chile, en todos los casos se admite la prórroga del período de sesiones, que en todos los casos incluye la solicitada por el Presidente y en nada menos que en ocho casos se conserva la figura de la Diputación Permanente ( con esa u otra denominación), singular herencia de las Cortes del Antiguo Régimen.

Por lo que toca al Ejecutivo sea cual sea el procedimiento de provisión todos los textos de referencia operan una definición de sus atribuciones según la técnica que tiene por norma de cabecera los arts. 170 y 171 del texto español, en este caso se hace pleno: diecisiete casos de diecisiete, lo que se corrobora por lo que toca a la posterior regulación de la figura ministerial, supuesto en el que sucede exactamente lo mismo. En el orden sigue el trato de los gobiernos locales, con un total de trece casos, el de la hacienda pública, con nueve casos, el de las fuerzas armadas con once casos. Para concluir siguen la pauta doceañista de agrupar protección y reforma de la Constitución siete casos.

Como puede verse, la influencia del texto gaditano no es capaz de dar cuenta de la estructura completa de los textos constitucionales en vigor, pero sí es capaz de dar razón de una parte de dicha estructura, aquella que gira en lo sustancial en torno a la doble determinación de nacionalidad y ciudadanía y al modo en que se regulan el Congreso y el poder ejecutivo.

Si contemplamos el cuadro desde una perspectiva nacional, si hacemos abstracción de los tres casos de Estados federales, es claro que existe una pauta común. Si incluímos estos últimos del cuadro I se sigue que existe una fuerte influencia en el caso de México, y una aun mayor en el de la actual constitución venezolana, existiendo dos casos claros de desviación de ese patrón común: el texto argentino, que siendo tributario del de 1853 refleja una muy fuerte influencia norteamericana, y el chileno, que se separa claramente de todos los demás ( y de los textos chilenos anteriores), cosa aun más notable si se considera que la históricamente más relevante ley fundamental chilena ( el texto de 1833) es uno de los que con mayor fidelidad siguen el patrón doceañista. $\mathrm{Y}$ es que el nacionalismo radical discurre a veces por extraños vericuetos. El texto chileno actual debe más

\footnotetext{
${ }^{9}$ Además de en el caso chileno no lo es ni en el argentino ni en el mejicano al ser estos estados federales en los que se sigue la pauta del art.1. de la Constitución USA, cosa que curiosamente no se da en el texto venezolano, en el que existe una cuidadosa diferenciación entre las reglas definitorias de la competencia federal y aquellas otras que determinan las atribuciones del Legislativo federal.
} 
a las leyes fundamentales del régimen franquista y al texto francés de 1958/62 que la propia tradición constitucional nacional.

\section{NACIONALIDAD Y CIUDADANÍA}

A la hora de definir quiénes son miembros del cuerpo político,cuáles son sus deberes, y quiénes, además de serlo, tienen acceso al proceso político al ser titulares de derechos políticos el texto gaditano sigue una técnica muy particular: ubica en una parte diferenciada del texto las reglas que determinan la pertenencia, esto es la nacionalidad, aquellas otras que determinan cuales de los nacionales son políticamente activos, es decir, son ciudadanos, y en que supuestos el ejercicio de la ciudadanía resulta suspendido. Obviamente hay partes enteras de la regulación gaditana que han devenido obsoletas, así, por ejemplo, las reglas que presuponen la esclavitud, las que privan de derechos políticos a las castas, que se introdujeron en el texto español a partir de la propuesta de los diputados americanos en las Cortes, aunque sería más exacto decir de los diputados sudamericanos en las $\operatorname{Cortes}^{10}$, o la regla que priva del ejercicio del sufragio a quienes se hallen en la situación de sirvientes domésticos. No obstante la existencia de regulaciones sobre la materia y la ordenación de ella según el patrón gaditano son, a la fecha, ampliamente mayoritarias. Tan solo dos casos, el argentino y el nicaragüense, han abandonado de manera completa el modelo doceañista. Por el contrario en al menos seis casos ( Bolivia, Chile, Colombia, Honduras, El Salvador, México y la Republica Dominicana) lo mantienen en su integridad, en tanto que en un caso, el de El Salvador, se identifican nacionalidad y ciudadanía. De otro lado, en los textos de Guatemala y Paraguay está presente la diferenciación, pero no se contempla en disposición específica la suspensión de la ciudadanía, que sí se contempla en el caso uruguayo aun cuando este no tiene un tratamiento constitucional de la cuestión de fondo, deferida a la legislación ordinaria, cosa que también sucede en el texto peruano vigente. Finalmente en doce casos sobre diecisiete la Constitución contempla deberes constitucionales de modo específico, si bien hay

${ }^{10}$ Como las castas tenían una presencia insignificante en la Nueva España los diputados a Cortes por México ( algunos de ellos padres de la independencia y el federalismo, y no por casualidad) pudieron tener la coherencia de combatir la exclusión de las castas, que sostenían peruanos y neogranadinos. De hecho en las primeras constituciones de Venezuela y Nueva Granada se procedía a la exclusión de las castas bien que, siguiendo el consejo de Blanco-White, por la técnica indirecta de exigir requisitos censitarios Así el art.15 del texto grancolombiano de 1821 o el art.15,C.II, s.1 del texto venezolano de 1811 por lo que toca en ambos casos a los electores primarios. 
que hacer notar que en este caso los deberes suelen ubicarse sistemáticamente tras la declaración de derechos, cosa que no sucede en 1812 por carecer el texto español de esta última.

Si bien no resulta extraño que la cuestión de la pertenencia nacional se afronte y resuelva en el texto constitucional, lo que parece relevante en este caso es el trato continuo de nacionalidad, ciudadanía, suspensión, asociado a la presencia de una determinación de deberes constitucionales. Respecto de estos últimos hay que reseñar que todos los textos que los comprenden incluyen los deberes de servicio de armas y fiscal, de un modo u otro ( según se asocie o no a la supremacía constitucional) algo similar sucede con el deber de fidelidad a la Constitución, algo menos frecuente es que figure el deber patriótico, y, desde luego, ninguno mantiene la ingenuidad del segundo inciso del art. 6 del texto español: el deber de ser justos y benéficos ${ }^{11}$. No obstante lo cual no parece que al aliento eticista que se halla detrás de tal prescripción doceañista se halle precisamente ausente de al menos algunas Constituciones en vigor.

En resumidas cuentas las cosas viene a aparecer más o menos del siguiente modo:

A la vista de la influencia que el texto español de 1978 ha venido a tener en algunas Constituciones latinoamericanas posteriores ( los casos de Guatemala o Colombia, por ejemplo) tal vez convenga señalar aquí que, a diferencia de todos los textos constitucionales españoles anteriores a la Guerra Civil, la vigente no contiene la determinación de las reglas que fijan quienes son miembros del cuerpo político: el art.11 CE remite directamente dicha cuestión a la ley. Y ningún texto español posterior a 1833 conserva la cuidadosa diferenciación constitucional entre nacional y ciudadano que se halla en el texto doceañista.

${ }^{11}$ En este sentido el texto vigente más desarrollado, a mi juicio al menos, es el del texto venezolano de 1999. 
Cuadro II. Nacionalidad, ciudadanía, suspensión y deberes constitucionales

\begin{tabular}{|c|c|c|c|c|}
\hline & Nacionalidad & Ciudadanía & Suspensión & C. Deberes \\
\hline \multicolumn{5}{|l|}{ Argentina } \\
\hline Bolivia & $36 / 37$ & $40 / 41$ & 42 & 8 \\
\hline Chile & 10 & 13 & 16 & 22 \\
\hline Colombia & 96 & 98 & 98 & 95 \\
\hline Costa Rica & & & & 18 \\
\hline Ecuador & & & & 97 \\
\hline El Salvador & & 71 & 74 & 73 \\
\hline Guatemala & 144 & 147 & & 135 \\
\hline Honduras & $22 / 24$ & 36 & 41 & 38 \\
\hline Mexico & 30 & 34 & 38 & $31 / 36$ \\
\hline \multicolumn{5}{|l|}{ Nicaragua } \\
\hline Panamá & $9 / 11$ & 125 & 127 & \\
\hline Paraguay & 146 & 152 & & \\
\hline Perú & & & 153 & 38 \\
\hline R. Dominicana & 11 & 12 & 15 & 9 \\
\hline Uruguay & & & 80 & \\
\hline Venezuela. & 33 & 39 & & $130 / 135$ \\
\hline
\end{tabular}

Nota. El art.5 de la C. chilena conserva la regla según la cual la soberanía reside esencialmente en la Nación. La uruguaya conserva las cláusulas de los arts.1 y 2 de la nación como asociación, su libertad e independencia y la proscripción del patrimonialismo ${ }^{12}$.

En este caso lo que se conserva es básicamente el patrón básico, no sucede lo mismo con las normas singulares que aquel comprende, no en vano tanto el Derecho Civil como la realidad social han venido a cambiar sustancialmente desde principios del siglo XIX a finales del siglo XX, no obstante sigue habiendo en esta materia un fondo normativo común, por más que el mismo no deriva tanto de la influencia doceañista en si, cuanto de una tradición jurídica compartida uno de cuyos rasgos comunes radica precisamente en la conservación de la tradición romanística que favorece el ius soli frente al ius sanguinis a la hora de determinar la nacionalidad, y, al hacerlo, da preferencia a la concepción cívica de la nación frente a las concepciones

${ }^{12}$ Encontrar un eco del decreto I de $24 / 09 / 1810$ en el texto uruguayo que, en su estado actual, cuenta con algo más de quince años, no deja de ser enternecedor. 
étnicas de la misma, a las que es propio otorgar primacía al principio de ascendencia. El hecho de que tanto el constitucionalismo latinoamericano como el peninsular se funden en una concepción cívica de la nación se debe más a aquella tradición jurídica compartida que a influencias posibles de texto determinados.

\section{LA ORDENACIÓN DEL CONGRESO: ORGANIZACIÓN Y FACULTADES}

La posible influencia del texto gaditano en la regulación del Congreso latinoamericano debiera tropezar con un obstáculo nada desdeñable: desde la Emancipación la tendencia mayoritaria del constitucionalismo hispanoamericano ha sido favorable al bicameralismo, a un bicameralismo en el que la versión USA del mismo ha tenido mucha mayor influencia que las versiones europeas de segundas cámaras de ordenación adecuada al principio democrático ${ }^{13}$. En principio cabría esperar que fuera del formato de la regulación del Congreso las reglas en el mismo contenidas deberían ser muy distintas, no solo por la tendencia a una regulación más detallada, sino sobre todo porque en el funcionamiento de las Cámaras parlamentarias y en su regulación han ido adquiriendo una importancia creciente cuestiones no previstas ni previsibles en los inicios del s. XIX, asi el deslizamiento a favor de un Parlamento de comisiones permanentes especializadas, la incidencia de las fracciones parlamentarias en el funcionamiento de las Asambleas y en su organización. No obstante lo cual alguna influencia, recibida normalmente a través de la propia tradición legislativa nacional, si es detectable. Como puede verse en el cuadro adjunto

${ }^{13}$ En el derecho constitucional europeo y español del s. XIX la Cámara Alta viene sistemáticamente entendida como una institución destinada a dar a una elite social una participación específica en el proceso político. Es esencialmente un medio para satisfacer la exigencia de momento aristocrático en una forma del gobierno que llamaríamos mixta en la terminología clásica. Si hacemos abstracción de alguna excepción puntual ( las leyes mexicanas de 1836, por ejemplo) esa idea es ajena a la tradición constitucional americana, que no va más allá de procurar una cierta representación de notables.

(C) UNED. Revista de Derecho Político 
Cuadro III. La ordenación de la Legislatura

\begin{tabular}{|l|c|c|c|c|c|c|c|c|c|c|c|}
\hline & $+25^{\mathrm{a}} \mathrm{a}$ & ES & Arra, & IAC & $3 \mathrm{mS}$ & $1 \mathrm{~m} . P$ & S.Ex. & V.M. & q. Con & q.dec & D.P. \\
\hline Ar. & 48 & 73 & 48 & 105 & & & 63 & 106 & 64 & & \\
\hline Bol. & 61.3 & & & 49 & $46-$ II & $46 . I \mathrm{I}$ & 47 & 103 & 48 & & 82 \\
\hline Chile & & & 44 & 54 & & & 52 & 37 & & & \\
\hline Col. & & & & & & & 138 & 208 & & 145 & \\
\hline CR & & & & 109 & & & 118 & 145 & & 119 & \\
\hline Ecu & 127 & & & 135 & & & 133 & & & 123 & \\
\hline El S. & 126 & 82 & & 127 & & & & & & & \\
\hline Gua. & & & & $160 / 4$ & & & 158 & 168 & & 159 & 163 \\
\hline Hond. & & 198 & & 199 & & 189 & 190 & & 192 & & 207 \\
\hline Mex. & & $55 . V I$ & $55 . I I I$ & & & & 67 & & 63 & & 78 \\
\hline Nic. & & 134.2 & & 134.2 & & & & & 141 & & \\
\hline Pana. & & & 147.5 & & & & 143 & & & & \\
\hline Par. & 221 & 197 & & 198 & & & 184 & & 185 & & 218 \\
\hline Perú & 90 & & & 91 & & & & 129 & & & 101 \\
\hline R.D. & 25 & & & & & 33 & 33 & & 30 & 27 & \\
\hline Uru. & 90 & & & 91 & & & 104 & 180 & 109 & & 127 \\
\hline Ven. & & & 188.3 & 189 & & & 220 & 245 & & & 195 \\
\hline
\end{tabular}

Leyenda: +25a: edad minima; ES: prohibición clero; Arra. : arraigo; IAC: incompatibilidad altos cargos de la administración central; $3 \mathrm{mS}$. Sesion de tres meses; $1 \mathrm{~m}$. P.: prórroga por un mes; S.Ex: sesion extraordinaria; V.M.: asistencia ministros sin voto; q Con.: quórum de constitución; q.dec: quórum de decisión; DP: diputación permanente.

Así, en ocho casos se conserva la regla doceañista de los 25 años de edad para acceder al Congreso, aun cuando la mayoría de edad ha descendido desde entonces, en seis casos se conserva la exclusión de los ministros de la religión, en cinco se mantienen las exigencias de arraigo en el distrito electoral para poder ser elegido diputado o senador por el mismo, en catorce casos el desempeño del cargo parlamentario es incompatible con los altos cargos de la administración, pero no se sigue la rígida regla norteamericana de incompatibilidad total entre empleo público y escaño, en un caso se conserva el período de sesiones ordinarias de 1812: 3 meses y en tres la prórroga tiene la duración prevista en el texto español, esto es un mes, en catorce casos se contempla la posibilidad de convocar sesiones extraordinarias, cosa tanto más notable cuando se considera que la organización dominante de las sesiones del Congreso cubre normalmente del orden de dos período de sesiones y en casi ningún caso es inferior a seis meses en dos períodos ordinarios, en nueve casos se conserva la regla doceañista que prescribe que los ministros pueden intervenir en las sesiones del Congreso con voz pero sin voto, en ocho casos el quórum de constitución de la Cámara sigue siendo el fijado en Cádiz y en cinco lo es el de decisión, finalmente en ocho casos se conserva la figura de la Diputación Permanente, como ya se señaló. No está mal después de doscientos años. 


\section{DOSCIENTOS AÑOS DESPUÉS. LA INFLUENCIA DE LA CONSTITUCIÓN...}

Si hay continuidad significativa en lo que toca a la organización la misma es aún mayor en lo que afecta a los poderes atribuídos al Congreso. Ya se ha observado que el derecho constitucional latinoamericano sigue la pauta de 1812 al determinar los poderes del Congreso mediante el recurso a una enumeración taxativa de los mismos, técnica que procede de la usada en el art.131 del texto español. En este punto, y pese a los enormes cambios que ha sufrido la concepción del papel del Estado, el grado de continuidad es significativamente mayor que en el caso anterior. Por de pronto todos los textos constitucionales atribuyen al Congreso el poder de legislar ${ }^{14}$, como no podía ser menos y no es por ello significativo, no obstante lo cual un examen detallado permite apreciar la continuidad ya señalada:

\section{Cuadro IV. Las facultades de la Legislatura}

\begin{tabular}{|l|c|c|c|c|c|c|c|c|c|c|c|c|c|c|c|c|}
\hline & Leg & Int. & J.PR & Trat. & T.Ex & Emp. & Con. & Gas. & Imp. & Deu. & Rep. & Cuen & BN & Mon & PM & R.M. \\
\hline Bol & 59.1 & 59.1 & 68.3 & & 59.15 & 59.17 & 59.14 & & 59.3 & 59.5 & 59.2 & 59.11 & 59.7 & 59.9 & 59.9 & 62.3 \\
\hline Chi & & & & & 60 & & 60 & & & 60 & & & 60 & 60 & 60 & 48 \\
\hline Col. & 150.1 & 150.1 & 192 & & & & & 150.11 & 150.12 & 150.9 & & & 150.9 & 150.13 & 150.13 & 178.3 \\
\hline CR & 121.1 & 121.1 & 126.8 & & 121.5 & & & & 121.13 & 121.15 & & & 121.14 & 121.17 & 121.17 & 121.9 \\
\hline Ecu. & 130.5 & 130.5 & 130.1 & & & & & & 130.6 & & & & & & & 130.9 \\
\hline El S & 131.5 & 131.5 & 131.14 & & 131.29 & 131.9 & & & 131.6 & 131.12 & & & & 131.13 & & \\
\hline Gua & $171 \mathrm{a}$ & & $165 \mathrm{~b}$ & $171 \mathrm{~L}$ & & & & & $171 \mathrm{c}$ & $171 \mathrm{i}$ & & $171 \mathrm{~d}$ & & $171 \mathrm{~h}$ & & $165 \mathrm{~h}$ \\
\hline Hon & 205.1 & 205.1 & 205.12 & & 205.26 & & 205.25 & & 205.35 & 205.36 & & & 205.41 & 205.36 & 205.34 & \\
\hline Nic. & 138.1 & 138.2 & & 138.11 & & & & & 138.26 & & & & & & & 138.3 \\
\hline Pan. & 153 & & & & & & & & 153.10 & & & 153.8 & 153.9 & 153.8 & & 155 \\
\hline Par, & 202.2 & & 202.14 & & & & & & & 202.10 & & 202.20 & 202.7 & & & 225 \\
\hline Peru & 102.1 & 102.1 & 116 & & 102.8 & & & & & 102.5 & & 102.4 & & & & 117 \\
\hline R D & 37.23 & & 54 & & & & & & 37.1 & 37.13 & & 37.2 & 37.4 & & & 23 \\
\hline Uru & 83 & & 158 & 85.7 & 85.11 & 85.13 & 85.8 & & 85.4 & 85.6 & & 85.5 & & 85.10 & 85.10 & 147 \\
\hline Ven & 187.1 & & & 187.18 & & & & & & & & & 187.12 & & & 223 \\
\hline
\end{tabular}

Leyenda: Leg: legislar; Int.:interpretar las leyes; JPR: juramento del Presidente; trat: aprobación parcial de tratados;T.Ex: autorización de entrada de tropas extranjeras; Emp.: decisión sobre los empleos públicos; Con: contingente militar; Gas.: aprobación del gasto; Imp.: aprobación de los impuestos ; Deu: aprobación empréstitos; Rep:reparto de las contribuciones; Cuen: aprobación de las cuentas del estado; $\mathrm{BN}$ : bienes nacionales; Mon: moneda; PM: pesos y medidas; RM: responsabilidad ministerial. ${ }^{15}$

${ }^{14}$ En el cuadro no figura el caso chileno porque es el único caso en el que se ha abandonado el concepto formal de ley para sustituirlo por uno material. Siendo en este una regulación extravagante en el contexto latinoamericano.

${ }^{15}$ Las referencias de 1812 son, por este orden, art.132.1; art.154, art,131.2; art.131.7; art.131.8; art.131.14; art.131.13; art.131.12; art.131.15, art.131.14, art.131.15; art.131.16; art.131.18; art.131.19; art.131.20; art.131.21; art.131.25.

(C) UNED. Revista de Derecho Político 
Por de pronto en ocho casos se conserva la facultad del Congreso de efectuar la interpretación de la ley, esto es se viene a conservar la figura del referé legislatif de origen francés, por más que su razón de ser, negar al juez el poder de interpretar, se haya dejado de lado hace mucho tiempo. En trece casos se conserva la regla constitucional que obliga a que el juramento y toma de posesión del Presidente se haga ante el Congreso, en al menos cuatro casos se conserva el reparto del poder sobre los tratados con el Ejecutivo, en siete casos se mantiene la regla que obliga a obtener autorización parlamentaria para el caso de entrada de tropas extranjeras en territorio nacional, en tres casos se mantiene la competencia parlamentaria sobre la determinación de los empleos en la Administración y en cuatro la autorización anual de contingente militar. En no menos de trece casos tiene el Congreso el monopolio de la facultad de establecer impuestos, y, en lógica consecuencia, compete al Congreso la decisión sobre el crédito y la deuda del Estado, en no menos de siete casos se asigna al Congreso la facultad de aprobar las cuentas, en tanto que en nueve se asigna a la Legislatura la competencia sobre el uso y destino de los bienes nacionales, en otros nueve el Congreso decide sobre el signo monetario, en tanto que en seis se conserva la arcaica regla sobre la determinación parlamentaria del sistema de pesos y medidas, finalmente en trece casos corresponde al Congreso iniciar el procedimiento de exigencia de responsabilidad jurídica a los ministros, siguiendo el patrón de la actualización del juicio de residencia establecido en Cádiz ${ }^{16}$.

Si dejamos de lado los casos de México y Argentina por la razón ya señalada de la recepción del modelo de reparto de competencias entre la federación y los Estados que ambos textos toman del modelo USA y procedemos a un examen por textos el cuadro anterior muestra con claridad que los mismos pueden ser ordenados en tres grupos según la influencia que el texto español ejerce a la hora de determinar en concreto las atribuciones del Congreso: un primer grupo estaría formado por aquellas constituciones en las que de los dieciséis ítems considerados la ley fundamental registra por encima de los dos tercios, de lo que se sigue que, en lo que en este apartado se trata, la influencia del texto gaditano es mayor, aquí se situarían los casos de Bolivia, Colombia, Costa Rica, Honduras y Uruguay; un segundo grupo, ocuparía una posición intermedia reuniendo un número de ítems que se agruparía en el entorno del cincuenta por ciento ( por más que la media sea algo mayor) aquí se insertarían los casos de Chile, El Salvador, Guatemala, Perú y la república Dominicana. Finalmente quedaría un grupo que reuniría los textos de menor influencia doceañista en la definición de las atribucio-

${ }^{16}$ Que difiere del impeachment en su versión americana en que el tribunal que enjuicia no es el Senado a título de jurado de enjuiciamiento, sino la suprema corte. 
nes de la Legislatura donde se ubicarían los casos de Ecuador, Nicaragua, Panamá, Paraguay y Venezuela. Tal vez no sea precisamente una casualidad que se trata casi siempre ( pero no siempre) de los textos más morigerados a la hora de determinar las atribuciones del Congreso. La influencia cuantitativamente más destacada se da en dos casos: el de Bolivia ( 14 items sobre 16) y el de Uruguay (12 sobre 16), y ello sin contar con el dato según el cual algunas atribuciones que figuran en el texto español y no se insertan en el o los preceptos específicos destinados a determinar in concreto el poder del Congreso en los textos latinoamericanos, si figuran en disposiciones distintas de la Constitución, como sucede, por ejemplo con los planes de enseñanza ( art.131.22 del texto español), fomento de la industria ( art.131.21) o aduanas ( art.131.17)

Como vemos la influencia en lo que afecta a la estructura del texto va más allá de dicho nivel y viene a incidir en forma significativa en la definición de las reglas que detallan la extensión de los poderes del Congreso.

\section{EL PODER EJECUTIVO}

No cabe duda de que la regulación constitucional latinoamericana que con mayor probabilidad recibe influencia del texto de 1812 es la correspondiente a la definición y facultades del poder ejecutivo. Ha sido así desde la Independencia, cuyas primeras Constituciones que sean, además, algo posteriores en el tiempo al texto español modelan la figura del Presidente de la República a imagen y semejanza de la regulación que la Constitución de 1812 primero hace del Rey. El esquema general es constante: una cláusula definitoria seguida de una enumeración detallada de las facultades presidenciales, enumeración que sigue muy de cerca la propia del art. 171 del texto español, del que se separa porque el Presidente es algo más débil que el Rey ya que, a diferencia de éste, ningún Presidente, ni siquiera el vitalicio de los textos bolivarianos peruano y boliviano de 1826, consigue se le atribuya el poder de paz y guerra. En rigor el modelo no es tanto el Rey cuanto la versión dulcificada del monarca que opera el decreto CCXLVII al definir los poderes de la Regencia ${ }^{17}$. Ese esquema general se va repetir una y otra vez en los textos inaugurales de las nuevas Repúblicas, y puede verse, por ejemplo, en el texto peruano de 1823, en los venezolanos de 1819 y 1830 o en el uruguayo de este último año, sin apenas otra variante que sustituir una definición basada en el enunciado del art. 170 por otra que define al Presi-

${ }^{17}$ Como en el caso inglés el art. 195 habilita a las Cortes para fijar cuales de las atribuciones del Rey serán ejercidas por la Regencia.

(C) UNED. Revista de Derecho Politico 
dente como «administrador general de la República» que introdujo el texto venezolano de 1819 y tanta fortuna obtuvo hasta mediados del s. XIX. Tal vez la imitación más fiel, en cuanto resulta la más próxima al original, sea la que figura en el texto chileno de 1833 , sin duda uno de los más exitosos ${ }^{18}$. En esta materia no resulta fuera de lugar señalar que sobre la casaca presidencial luce ciertamente la banda con los colores patrios, pero si fijamos la vista en la casaca, y no en la banda, no tardaremos mucho en apreciar sobre la misma los entorchados del Virrey o del Capitán General, sucedáneos del Rey en la provincia.

No obstante sobre la figura del Presidente ha planeado siempre la sombra del homólogo estadounidense. Para lo que aquí interesa hay dos rasgos del diseño USA de la figura presidencial que en su día fueron objeto de abundante imitación, de la cual aún quedan residuos en el Derecho Constitucional de nuestros días: de un lado la necesidad del acuerdo del Senado por mayoría fuertemente reforzada para la ratificación de los tratados, por más que la admisión y desarrollo de los «acuerdos ejecutivos» haya privado de gran parte de su virtualidad a esa previsión; del otro la necesidad del «consejo y consentimiento» del Senado para el nombramiento de altos funcionarios en general, y oficiales superiores de las fuerzas armadas en particular. El transcurso del tiempo, el peso de la propia tradición y un mejor conocimiento del Presidente norteamericano realmente existente han conducido al progresivo eclipse de tal clase de disposiciones, por más que no falten algunos supuestos de supervivencia.

Si la técnica de definir la figura presidencial mediante una enumeración detallada de sus atribuciones, según el patrón sentado por el art.171 del texto español goza de buena salud, hasta el punto de ser poco menos que única para servir a tal fin en el Derecho Constitucional latinoamericano existente en el día, no ha sucedido lo mismo con la cláusula definitoria, sea esta la derivada del texto venezolano de 1819, la acuñada por el español, u otra. Aunque, como veremos en seguida su uso no ha desaparecido, ha dejado de ser lo que en su día fue, esto es una figura de uso poco menos que general. Dicho eclipse no resulta difícil de entender si se considera, en primer lugar, que tal cláusula no es indispensable, y que, de hecho, no existe en el caso del texto norteamericano; en segundo lugar que aun cuando la misma se entienda como una cláusula atributiva de poderes

${ }^{18} \mathrm{~A}$ mi juicio lo que explica el hecho sorprendente de que el art.24 de la actual constitución chilena defina al Presidente con las palabras del art.170 del texto gaditano no es otra cosa que la intención deliberada de vincular la figura presidencial con la de Portales, tomando al efecto la definición presidencial del texto constitucional de 1833, sin caer en la cuenta del lugar de procedencia. No sería la primera vez en la que los estrictos nacionalistas tengan imperfecto conocimiento de la propia historia 


\section{DOSCIENTOS AÑOS DESPUÉS. LA INFLUENCIA DE LA CONSTITUCIÓN...}

(y ese es el significado en la versión original) el mismo resultado se puede obtener trasladando al listado de facultades las que de la definición puedan seguirse, de lo que no son ejemplos lo que falta; finalmente cabe alegar algo tan simple como la economía. Con todo, el eclipse no deja de ser relativo: de los diecisiete textos que se consideran hay una cláusula definitoria de la figura presidencial en ocho casos, casi la mitad de la varianza. Como puede verse en el cuadro adjunto conservan dicha figura los textos de Argentina, Chile, Colombia, Ecuador, Guatemala,Perú, República Dominicana y Venezuela:

\section{Cuadro V. Las facultades del Poder Ejecutivo ${ }^{19}$}

\begin{tabular}{|c|c|c|c|c|c|c|c|c|c|c|c|c|c|c|c|c|c|}
\hline & CD & san. & Pro. & P.R. & I.L. & $\mathrm{NMg}$ & Emp & M.FA & $\mathrm{D}, \mathrm{FA}$ & A.E. & Inv & Gas. & Min & Pro. & S.Ex & $24 \mathrm{~h}$. & RM \\
\hline Arg. & 99.1 & & 99.3 & 99.2 & 77 & & 100.3 & & 99.14 & 99.7 & 99.10 & 99.5 & & 63 & 63 & & 100 \\
\hline Bol. & & & 74.2 & 96.1 & 71.1 & & 96.15 & & & 96.3 & 96.6 & 96.13 & 99 & 46.2 & 47 & 11 & 102 \\
\hline Chi. & 24 & 32.1 & 32.1 & 32.8 & 32.1 & 32.14 & 32.12 & 32.18 & 32.19 & 32.10 & 32.22 & 32.16 & 33 & & 32.2 & 19.7 & 35 \\
\hline Col. & 115 & 157 & 165 & 189.11 & 154 & & & 189.3 & 189.3 & 189.2 & 189.20 & 201.2 & 189.1 & & 138 & & 115 \\
\hline CR & & 140.3 & 140.3 & 140.3 & 123 & & 140.1 & 139.3 & $|145-16|$ & 145.12 & & & 139.1 & & 118 & 37 & 146 \\
\hline Ecu. & 164 & 153 & & 171.5 & 144 & & & 171.14 & & 171.10 & & 171.20 & 171.10 & & 133 & 24.6 & \\
\hline ES. & & 135 & 140 & 168.16 & 133 & & & & 168.12 & 168.5 & & 168.10 & 162 & & & & 163 \\
\hline Gua. & 182 & 177 & 177 & $183 c$ & 174 & & & $183 c$ & & 1830 & & & $183 \mathrm{~s}$ & & 158 & & $194 \mathrm{c}$ \\
\hline Hon. & & 215 & 215 & 245.11 & 213 & & & 245.16 & & 245.12 & & 245.24 & 245.5 & 189 & 190 & 71 & 248 \\
\hline Mex. & & & 89.I & 92 & 71 & 89.18 & & & 89.IX & $89 . \mathrm{X}$ & & 89.XIV & 89.II & & 89.XI & & 92 \\
\hline Nic. & & 141 & 141 & 150.10 & 140.2 & 150.14 & & & & 150.8 & & & 150.6 & & 150.7 & & 151 \\
\hline Pan. & & 162 & 162 & 179.14 & 159 & 195 & & & & 179.9 & & 179.12 & 178.1 & & 143 & 21 & 181 \\
\hline Par. & & & 204 & 238.3 & 203 & & 238.6 & 238.9 & 238.9 & 238.7 & 238.13 & & 238.10 & 184 & 184 & 12 & 238.5 \\
\hline Perú & 110 & & 108 & 118.8 & 107 & & & & 118.14 & 118.11 & & 118.21 & 122 & & 118.6 & 2.24 & 120 \\
\hline RD. & 55 & & 41 & 55.2 & 38 & & 55.1 & 55 & 55.14 & & 55.3 & 55.27 & 55.1 & & 33 & & \\
\hline Uru. & & 143 & 143 & 168.4 & 133 & & 168.9 & 168.2 & & & & & 174 & & 104 & 16 & 168.25 \\
\hline Ven. & 226 & & 214 & 236.10 & 204 & & 236.16 & 236.6 & & 236.4 & & 236.19 & 243 & & 236.9 & & \\
\hline
\end{tabular}

Leyenda: CD: cláusula definitoria; san.; sanción; Pro.: promulgación; P.R.: potestad reglamentaria Ileg: iniciativa legislativa; $\mathrm{NMg}$ : nombramiento de magistrados; Emp.: nombramiento empleados públicos; MFA: Mando de las Fuerzas Armadas; DFA: disposición de las FAS; A.E.: relaciones exteriores; Inv: decretar las inversiones; Gas: decidir sobre la aplicación del gasto; Min: nombramiento de ministros; Pro:: prorroga de las sesiones de la Legislatura; S.Ex: convocatoria de sesión extraordinaria; 24 h.: plazo detención gubernativa; RM: refrendo ministerial.

${ }^{19}$ Las referencias al texto de 1812 son, por su orden; art.142; art.154; art.171.1; art.171.14; art.171.4; art.171.5; art.171.8; art.171.9; art.171.10; art.171.12; art.347, art.171.16; art.107; art.162; art.290; art.225.

(C) UNED. Revista de Derecho Politico 
Si pasamos a las facultades que se asignan al Presidente ya se ha señalado que en todos los casos se sigue el patrón doceañista: hay una relación con vocación de exhaustividad de las atribuciones presidenciales, sin perjuicio de que preceptos constitucionales diversos asignen de modo puntual otras facultades no registradas en aquella. El Presidente tiene un importante papel en la producción normativa, así hereda del Rey la facultad de perfeccionar la ley mediante la sanción en 10 casos, procede a la promulgación en dieciséis y ejerce la iniciativa legislativa y ostenta la potestad reglamentaria en todos los supuestos. Probablemente es aquí donde la proximidad al Ejecutivo doceañista y la diferenciación con el Presidente USA es de mayor tamaño y relevancia. Si a ello unimos que el Presidente tiene la facultad de vetar las leyes adoptadas por el Congreso ( en general mediante una regulación claramente inspirada en la regulación norteamericana ) y que no solo puede interponerlo frente al conjunto de un proyecto de ley, sino también frente a disposiciones singulares del mismo, queda claro que en el diseño de la figura presidencial latinoamericana aparece el perfil del Presidente como una suerte de colegislador, perfil que no se registra fuera de la América ibérica.

Si en el terreno de la producción normativa el peso del modelo doceañista es aplastante no sucede lo mismo en lo que afecta a la organización de la judicatura. El texto español atribuye al Rey el nombramiento de los jueces y magistrados profesionales, normalmente a propuesta en terna del Consejo de Estado, según el patrón procedente de la Cámara de Castilla, que también se aplica a los nombramientos eclesiásticos que se siguen del patronato. En este punto el régimen de patronato ha desaparecido tiempo ha y con él el poder presidencial de nombrar para los cargos y beneficios eclesiásticos, que sí se conservaba en los textos constitucionales del período de la Independencia. En lo que a los nombramientos judiciales afecta el Derecho Constitucional latinoamericano reciente muestra una acentuada tendencia a imitar con mayor o menor fortuna la figura de origen europeo del Consejo de la Magistratura o del Poder Judicial aun así en cuatro casos ( Chile, México, Nicaragua y Panamá) el poder presidencial sobre los nombramientos judiciales siguen estando presente.

Otro caso es de los nombramientos de los empleados públicos. En esta cuestión la facultad originaria que, como en el caso español, comportaba la plena disposición sobre los empleos de la Administración del Estado, se ha visto progresivamente minorada por la influencia creciente del modelo funcionarial de «servicio civil», que comporta el reclutamiento de empleados públicos según técnicas basadas en los principios de mérito y capacidad, si bien resulta todavía común que haya una parte de dichos empleos plenamente disponibles por el Ejecutivo. Por ello no debe extrañar que al menos en ocho casos la correspondiente facultad figure en elenco de las atribuciones presidenciales. 
Por lo que toca al poder militar las reglas tomadas del modelo USA que restringían la plena disposición presidencial de los nombramientos militares, frecuentes en la fase inicial de la vida republicana ha ido menguando en importancia. En este punto la regulación gaditana cuenta con la particularidad de diferenciar cuidadosamente entre el «mando» y la «disposición» de las Fuerzas Armadas. En al menos cinco casos (Chile, Colombia, Costa Rica, Paraguay y República Dominicana) tal diferenciación se conserva en sus propios términos, en los demás o bien se contempla el «mando» sencillamente ( por ej. Ecuador) o bien se conserva la «disposición» ( Uruguay, pongamos por caso) aunque resulta obvio que se emplee uno u otro término, o los dos, la realidad no se ve alterada: es el Presidente el titular del poder militar y el director de la fuerza armada.

Si bien hay unanimidad en asignar al Presidente el papel de rector de la política exterior no siempre se expone del mismo modo, aquí la fórmula usada por el texto español ( dirigir las relaciones y nombrar personal diplomático) más o menos modificada es ampliamente seguida: quince supuestos sobre diecisiete. No sucede lo mismo con la facultad de decretar las inversiones en la Administración, probablemente porque el planteamiento de las cuestiones relacionadas con el gasto público han sufrido notable mudanza, aun así una facultad similar aparece en seis de los diecisiete casos examinados.Por el contrario la competencia sobre el gasto ( y no sobre la distribución) sí resulta frecuente, con doce casos sobre diecisiete.

Otra cosa sucede con el tratamiento constitucional de la figura ministerial. Esta existe siempre y sólo en un caso ( el argentino) no existe un capítulo, apartado o sección de la Constitución dedicado específicamente a contemplar la figura de lo que a veces se denominan ministros, y a veces secretarios, siguiendo la denominación algo arcaizante que se remonta nada menos que a las reformas administrativas de Felipe V. En todos los supuestos los de ministros son nombramientos de estricta confianza presidencial, y la mayor parte de los veces su tratamiento constitucional no va más allá de las previsiones del texto español. Y ello con independencia de si, en la práctica, el Presidente despacha individualmente con los ministros o si existe la práctica de la reunión del gabinete. Solo en algunos textos posteriores a 1980 puede encontrarse una regulación formal que contempla el Consejo de Ministros y su Primer Ministro ( caso del Perú, por ejem.) aunque siga tratándose de cargos de estricta confianza presidencial.

De raro puede calificarse el que se conserve la facultad presidencial de instar la prórroga del período de sesiones por el plazo de un mes, figura que sí aparece en el texto español. No es difícil entender por qué dicha prórroga sólo figura en cuatro casos, y solo en uno - el paraguayo - el texto es de reciente redacción, si se ha seguido la pauta de ampliar los períodos ordinarios, hasta el punto que 
son mayoría los supuestos en los que las sesiones ordinarias cubren más de la mitad del año, la utilidad de la figura deviene muy escasa. No obstante no sucede lo mismo con la facultad presidencial ( exclusiva o concurrente) de convocar sesiones extraordinarias que, en cuanto tales, se reúnen para orden del día determinado, en este supuesto la institución se ha conservado de modo prácticamente idéntico al del original, tan solo en un caso — el salvadoreño — se encuentra una apreciable desviación de lo que constituye una norma general.

Muy distinto es el supuesto del plazo máximo de privación de libertad meramente gubernativa, la estricta regla doceañista del plazo de 24 horas no es fácil de conservar ${ }^{20}$, pese a ello en nueve casos ese es el plazo que se conserva, si bien se ha desplazado de su ubicación original ( la ordenación del procedimiento criminal) a otra más apropiada: la declaración de derechos. Por último la figura ministerial comporta como lógica consecuencia de su condición de tal el instituto del refrendo, el modelo gaditano es peculiar en cuanto que define el refrendo ministerial como condición de validez de la orden del titular del Ejecutivo, en tales términos se conserva en catorce de los diecisiete casos, no uniéndose dicho requisito o no contemplándose expresamente tan solo en los textos de Ecuador, Venezuela y República Dominicana ${ }^{21}$.

El peso relativo de las atribuciones presidenciales que proceden de la Constitución de 1812, generalmente a través de la tradición constitucional de cada República, siendo variable es muy importante: en ningún caso sobre un total de diecisiete facultades consideradas, el peso de los preceptos de aquella procedencia se halla por debajo del cincuenta por ciento, siendo el peso más reducido de 9 atribuciones sobre las diecisiete que se contemplan, habiendo nada menos que siete casos en los que aquel se sitúa por encima de los dos tercios. El supuesto de máxima fidelidad al modelo gaditano se da en el caso de la Constitución chilena: dieciséis casos sobre diecisiete, cosa que no debe sorprender: el texto del gobierno militar buscó inspiración en la Constitución nacional con merecida reputación de Presidencia fuerte: el texto de 1833, y éste es, de los latinoamericanos de primera generación, aquel en el que la configuración del Poder Ejecutivo sigue con mayor fidelidad la Constitución española de 1812.

${ }^{20}$ De hecho ni la Constitución de 1837, ni la de 1845 , ni la non nata de 1856 lo conservan, desconstitucionalizando el plazo. Hay que esperar al texto democrático de 1869 para que reaparezca(art.3), regla que conservará el texto canovista de 1876 (art.4), sobrevivirá parcialmente en el art.29 de la Constitución republicana, que introducirá el plazo de setenta y dos horas hoy existente.

${ }^{21}$ Resulta obvio que prescindir del refrendo o no contemplarlo como condición de validez de la orden presidencial supone una significativa ampliación de la autoridad presidencial. 
Una de las diferencias de mayor relevancia que existen entre el diseño del Poder Ejecutivo en la constitución francesa de 1791 y la española de 1812, y que no se registra en el catálogo abierto de facultades regias del art. 171 del texto español tiene que ver con el sistema administrativo subyacente. En el caso francés las comunas son autónomas y se rigen por funcionarios electos, y lo mismo sucede con los departamentos, de tal modo que la administración local escapa al control de la Monarquía, que de ese modo queda privada de los recursos de todo tipo que departamentos y comunas gestionan, el modelo doceañista no es así. Si dejamos de lado que los jueces son de nombramiento regio y no de elección, en el sistema seguido por el texto español los ayuntamientos, si bien están integrados por funcionarios electos, se hallan bajo la supervisión de las diputaciones provinciales, a las que deben rendir cuenta anual de su actividad al darla de sus finanzas (art.323). A su vez las diputaciones provinciales ${ }^{22}$ también están formadas por funcionarios electos, ahora bien éstas no solo ejercen tutela sobre los ayuntamientos, es que están dirigidas por oficiales del Rey: en cada provincia las cuentas son responsabilidad de intendente (art. 326) y la diputación la preside un agente del gobierno central nombrado por el Rey, el Jefe Político, a quien compete el «gobierno político de las provincias» (art. 324 de la Constitución), de esta manera el Ejecutivo, a través de sus agentes, supervisa y controla los gobiernos locales. Pues bien, un sistema similar, centrado en una figura semejante al «jefe superior» o «político» del diseño gaditano puede contemplarse hoy: hay figura equivalente al jefe político en Chile (art.105), Colombia (art.303), Ecuador (art. 227), El Salvador (art.200), Panamá (art.249), Paraguay (art.161) o R. Dominicana (art.86). Siete casos, que no son grano de anís.

\section{LA AUSENCIA DEL PODER JUDICIAL}

La regulación de la judicatura no se va a tratar aquí en detalle por las razones de las que ya se ha hecho mención. Por de pronto porque no es de esperar que una Constitución contenga las bases de las leyes de procedimiento civil y criminal, como hace la Constitución gaditana. Eso tiene sentido en una Constitución de ruptura en la que se procura redactar una ley fundamental que contenga una definición casi completa del modelo de Estado que viene a sustituir el Antiguo Régimen que se liquida, carece de él cuando tratamos con textos constitucionales que tienen tras sí casi doscientos años de régimen constitucional, por muy bastardeado que este haya sido. Tampoco parece muy puesto en razón establecer una comparación entre un texto, el español, que trata de definir ex novo

${ }^{22}$ De las que se dijo que eran una diputación vasca. 
nada menos que toda la estructura de la organización judicial ( de una organización judicial nueva, nunca se insistirá bastante) cuando la misma responde a principio de radical novedad: para administrar un ordenamiento en el que la ley es una, y por ello la misma para todos, en la que opera el principio de igualdad ante la ley, en la que no hay otra justicia que la del Estado y en la que los privilegios han pasado para no volver.

Ya se ha señalado que todas las constituciones que venimos considerando conservan una organización, ahora ya tradicional, de una judicatura ordenada en tres niveles: jueces de partido y/o distrito; audiencias y/o cortes de circuito; tribunal supremo y/o Suprema Corte. No está de más recordar que esa organización de la judicatura en tres niveles de jueces profesionales es común tanto al constitucionalismo de ambas Américas como al europeo a partir de la Revolución francesa, y que ese carácter común se extiende con harta frecuencia hasta las denominaciones de los diferentes órganos jurisdiccionales. Asimismo se ha señalado que lo que en su caso puede resultar típico del modelo doceañista no es que conserve esa estructura tripartita; es que a la misma agrega un cuarto nivel, ubicado en la base de la pirámide judicial y formado por jueces a la vez legos y temporales. Finalmente se ha dicho con anterioridad que, sea cual sea la denominación de los órganos judiciales, en estos es perceptible la herencia de la organización judicial de la Monarquía, y que es en esta y no en el art.3 de la Constitución USA, donde hay que buscar los precedentes. Hora es de que lo justifiquemos.

El sistema legal norteamericano es un sistema de common law, un Derecho que es creado primariamente por la sociedad civil mediante las relaciones que la componen y que solo secundariamente comprende el Derecho escrito, un sistema en que el problema de la acreditación de la norma socialmente generada se resuelve mediante el reconocimiento de la misma por el juez a la hora de decidir contenciosos entre particulares, a cuyo efecto resulta indispensable una judicatura integrada por personal que conozca los negocios, porque es en ellos donde la sociedad crea la norma jurídica, y resulta funcional el uso intensivo del tribunal del jurado en todo tipo de litigios dado que, por naturaleza, el jurado está integrado precisamente por los miembros de esa sociedad que se autoordena generando nuevas normas jurídicas mediante su propio tráfico jurídico. Nada de todo ello existe en la America hispánica.

Las Repúblicas latinoamericanas han heredado de la colonia un sistema legal de inspiración romano-canónica y cuya estructura reposa sobre el principio de la primacía, general e incondicionada, del Derecho escrito. En consecuencia el operador jurídico debe tener adecuado conocimiento del Derecho legislado y el juez es un operador jurídico al que le es exigible que sea un perito en el Derecho 
escrito porque muy mayoritariamente es éste el que tiene que aplicar. Un juez que es concebido a partir de la idea, presente en Montesquieu ( no en vano magistrado el mismo), según la cual el juez es un mero aplicador de la ley que determina el Congreso, el juez como «la boca que pronuncia las palabras de la ley», un juez, pues, que no tiene que desempeñar el papel proactivo que es inherente al juez de «derecho común» y del que se espera, a los efectos de la imparcialidad necesaria, que sea ajeno al ejercicio de otras profesiones jurídicas. Nada revela mejor esa radical diferencia que el hecho según el cual, a imagen y semejanza de lo que prevé el art. 131.1. del texto gaditano, sea tan frecuente en el Derecho Constitucional ultramarino la previsión de conformidad con la cual es privativo de la Legislatura la facultad de interpretación de la ley, regla que, como hemos visto, se conserva en ocho de los diecisiete textos examinados.

Siendo así las cosas resulta claro que en aquellos casos en los que, pro forma, observamos una imitación mas o menos fiel de la organización de la judicatura establecida en el caso norteamericano nos hallaremos ante un ejemplo de seudomorfismo: las mismas o similares palabras encubren situaciones radicalmente distintas. Por eso podemos detectar las puñetas del juez de la Real Audiencia en la persona del ministro de la Suprema Corte.

\section{CONCLUSIÓN}

Si bien es cierto que lo que hay en las páginas anteriores no pasa de ser una primera aproximación, ésta sí permite sostener, siquiera sea a título provisional, que al menos una parte de la Constitución española de 1812 se halla en el trasfondo de una parte del Derecho Constitucional latinoamericano contemporáneo. Cabe sospechar que el vehículo mediante el cual la obra del Oratorio de S. Felipe acabe influyendo en textos redactados a finales del siglo XX o principio del $\mathrm{XXI}$, no es otro que la tradición constitucional nacional, al menos eso sugiere el hecho de que esa influencia doceañista tienda a ser mayor en aquellos casos ( México, Uruguay ) en los que la misma fue particularmente intensa en la fase inicial de la vida republicana y, en su momento, tuvo destacada presencia en los textos constitucionales históricos que fundan la tradición constitucional nacional. Lo que viene a significar que salir de la provisionalidad señalada exige una serie de estudios de casos. No oculto que alimento la sospecha de que en casi todos los casos dicho estudio sacaría a la luz algo similar a lo que ocurre en España con el Derecho Constitucional de la monarquía liberal: los textos constitucionales son numerosos y diversos, pero a esa variedad subyace una fuerte continuidad de fondo: la última ley fundamental de la monarquía, la de 1876, obtiene la mayoría de 
sus preceptos de las Constituciones que la preceden, y una parte sustancial de sus enunciados permanece en presencia constante desde el texto progresista de 1837.

Sea o no sea así, lo que me parece suficientemente acreditado es que la concepción dominante acerca de la naturaleza y funciones del Congreso y del Presidente de la República resulta ininteligible si no se considera que está marcada a fuego por la correspondiente de las Cortes y el Rey en la primera Constitución española, que casi siempre es, al mismo tiempo, la primera de la parte americana de la Monarquía. Puede que no se conserve la idea básica sobre la que el diseño de ambos poderes se basa, puede que no se haya conservado la idea de Congreso y Presidente entendidos como «potestad», que traen causa de su entendimiento en términos de «oficio», de lo que se sigue que el reparto del poder entre el Congreso, el Presidente y los Tribunales no puede ser arbitrario porque a cada rama del gobierno, a cada «oficio», le corresponden naturaliter determinadas facultades, sin las cuales no sería tal, lo que, por cierto, explicaría sin dificultad las diferencias con los homólogos norteamericanos y la razón por la que limitaciones iniciales de algunas facultades presidenciales han terminado por desaparecer.

Alfara del Patriarca, verano/otoño de 2011.

Title:

TWO HUNDRED YEARS LATER. THE INFLUENCE OF THE SPANISH CONSTITUTION OF 1812 IN THE LATIN AMERICAN CONSTITUTIONS IN VIGOR. AN APPROACH

Summary:

1. INTRODUCTION. 2. THE DISTRIBUTION OF THE POWER IN MODELO DOCEAÑISTA. 3. NATIONALITY AND CITIZENSHIP. 4. THE ARRANGEMENT OF THE CONGRESS: ORGANIZATION AND FACULTIES. 5. THE EXECUTIVE AUTHORITY. 6. THE ABSENCE OF THE JUDICIAL POWER. 7. CONCLUSION

\section{Resumen:}

El artículo tiene por objeto el estudio de la influencia de la Constitución de Cádiz de 1812 en las Constituciones latinoamericanas vigentes, incorporando el análisis de la Constitución americana de 1787 y la francesa de 1791. El estudio comparativo se realiza sobre la estructura de los textos constitucionales, la nacionalidad y la ciudadanía y el poder legislativo, ejecutivo y judicial. El estudio sostiene que, siquiera a título provisional, al menos una parte de la Constitución do- 
ceañista se halla en el trasfondo de una parte del Derecho Constitucional latinoamericano contemporáneo, aserto que habría que corroborar con una serie de estudios de caso para elevarla a definitiva.

\begin{abstract}
:
The article intends the study of the influence of the Constitution of Cadiz of 1812 in the effective Latin American Constitutions, incorporating the analysis of the american Constitution of the 1787 and french of 1791. The comparative study is made on the structure of constitutional texts, the nationality and the citizenship and the legislative, executive and judicial power. The study maintains that, at least for a reason or purpose provisional, at least one part of the Constitution of Cadiz is in background of a part of the Constitutional Right latin american contemporary, assertion that would be to corroborate with a series of case studies to elevate it to definitive.
\end{abstract}

\title{
Palabras clave:
}

Constitución de Cádiz, Constituciones latinoamericanas, influencia.

Key words:

Constitution of Cadiz, latin american Constitutions, influence. 
